\section{MEMÓRIAS DE ATENAH: TRAJETÓRIAS DE MULHERES BRASILEIRAS NA CORRIDA DE AVENTURA}

\author{
MEMORIES OF ATENAH: THE HISTORIES OF BRAZILIAN WOMEN IN \\ ADVENTURE RACE C
}

MEMORIAS DE ATENAH: TRAYECTORIAS DE MUJERES BRASILEÑAS EN LA CARRERA DE AVENTURA C

doi' https://doi.org/10.22456/1982-8918.100848

(iD) Fabiana Duarte e Silva*<fabiduartes@hotmail.com>

(iD Ludmila Mourão** <mouraoln@gmail.com>

D Gisele Maria Schwartz** <gisele.schwartz@unesp.br>

(iD) Bruna Silveira Chaves** <profabrunachaves@gmail.com>

*Prefeitura de Juiz de Fora. Juiz de Fora, MG, Brasil.

**Universidade Federal de Juiz de Fora. Juiz de Fora, MG, Brasil.

Resumo: Este artigo investigou a trajetória de vida esportiva das atletas da equipe de corrida de aventura (CA) Atenah, formada exclusivamente por mulheres. A CA é uma competição multiesportiva, formada por equipes mistas, com ao menos uma pessoa de gênero distinto dos demais membros. A pesquisa qualitativa de caráter descritivo consistiu em entrevista semiestruturada com cinco atletas da equipe Atenah. Observou-se que as atletas utilizam estratégias de "subversão" e "conservação", segundo Bourdieu, e constituem "agências", segundo a teoria de Dworkin e Messner. O fato de organizarem uma equipe exclusivamente feminina pode ser entendido como "estratégia de subversão" ou a constituição de "agência resistente". Paradoxalmente, utilizaram "estratégias de conservação" para se manterem no esporte, configurando, assim, "agência reprodutiva". Conclui-se que o apoio e incentivo da família foi fundamental para o sucesso das atletas, porém, o engajamento das mulheres na corrida de aventura pode ser ameaçado pelas instituições do casamento e da maternidade.

Palavras chave: Esportes. Natureza. Estudos de Gênero. Mulheres.
Recebido em: 05-03-2020 Aprovado em: 28-07-2020 Publicado em: 27-11-2020

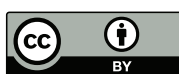

Este é um artigo publicado sob a licença Creative Commons Atribuição 4.0 Internacional (CC BY 4.0).

elSSN: 1982-8918 


\section{INTRODUÇÃO}

A corrida de aventura (CA) é uma competição multiesportiva na qual participam equipes formadas por mulheres e homens, com o objetivo de percorrer longas distâncias em diferentes modalidades esportivas, tais como mountain biking ${ }^{1}$, trekking ${ }^{2}$, canoagem, técnicas verticais e orientação cartográfica ${ }^{3}$, no menor tempo possível, exigindo o máximo de sua resistência física e psíquica, já que as provas comumente se desenvolvem em locais selvagens. ACA é um esporte pouco conhecido e pouco divulgado na mídia tradicional brasileira. Talvez por conta da complexa logística que requerem as provas de longa duração e pelo fato de acontecer em ambientes inóspitos.

Normalmente, a CA é praticada em equipes de duas a quatro pessoas. $\mathrm{O}$ quarteto misto, formação exigida no campeonato mundial, tem a obrigatoriedade de ter pelo menos um membro de sexo oposto junto aos demais. A formação com três homens e uma mulher é a mais tradicional nas principais competições do Brasil e do mundo. Nesse sentido, a escassez de investigações sobre mulheres envolvidas nas corridas de aventura e a singularidade de sua participação nesse tipo de competição representam a inquietação geradora deste estudo.

$\mathrm{Na}$ revisão de literatura foi possível perceber que a maioria dos estudos sobre corrida de aventura dá ênfase aos aspectos fisiológicos do esporte. Dentre as pesquisas qualitativas realizadas nesse campo, a maioria dos debates acadêmicos permeia discussões acerca da adesão ao esporte, perfil dos atletas e aspectos motivacionais dos praticantes. Poucas pesquisas contemplam discussões sobre relações de gênero na CA. Apesar de percebermos um aumento histórico na adesão de mulheres aos esportes de aventura em geral, muitos autores observam que há razões importantes para examinarmos criticamente se as mulheres estão fazendo reais incursões nesses esportes. Holly Thorpe (2011), por exemplo, discute que o progresso positivo das mulheres no snowboarding é superficial, e que elas ainda são marginalizadas no meio. Já Becky Beal (1996) descreve como os jovens no skate enfatizavam as diferenças entre homens e mulheres como justificativa para criar diferentes papéis para elas, sendo estes papéis inferiores.

Em estudo específico no campo da CA, Joanne Kay e Suzanne Laberge (2004) sugerem que a CA se constitui em um lugar de legitimação da dominação masculina no esporte, a partir do momento em que as equipes são formadas em conformidade mínima com a regra de gênero, na configuração de apenas uma mulher, e nunca de três mulheres e um homem, por exemplo. Segundo Schwartz et al. (2013), em estudo que analisou a presença feminina em esportes de aventura, encontrou que a aceitação das mulheres na CA pode estar relacionada ao cumprimento da regra e não à mudança de valores.

\footnotetext{
1 O mountain biking é uma das modalidades do ciclismo, praticada em estradas de terra, trilhas e montanhas, com bicicleta apropriada (PFEIFFER; KRONISH,1995).

2 O trekking pode ser considerado uma caminhada em ambientes naturais (florestas, montanhas, cerrados e trilhas) (BITENCOURT; AMORIN, 2006).

3 Técnica de orientação por mapa e bússola muito utilizada pelo exército brasileiro, o qual, inclusive, promove competições de orientação, nas quais o atleta precisa passar por pontos de controle predeterminados e assinalados no mapa fornecido pela organização.
} 
O presente artigo investigou a trajetória esportiva das atletas integrantes da Equipe Atenah, única equipe formada exclusivamente por mulheres de que temos notícia no Brasil (ADVENTUREMAG, 2001; ATIVO, 2009). Este estudo se insere na temática dos Estudos de Gênero e contribui para desconstruir o chamado determinismo biológico, que muito dificulta e restringe a prática de esportes considerados viris, de força e de contato, por parte das mulheres (GOELLNER, 2013).

O artigo se inicia situando o campo de pesquisa e métodos investigativos, seguido do contexto histórico acerca da formação da Equipe Atenah para, posteriormente, apresentar as categorias de análise que emergiram no estudo, sob os títulos: "Mulheres transgredindo, resistindo e desafiando os limites na CA" e "Das dificuldades às estratégias de participação utilizadas pelas atletas de CA". Finalizando com considerações acerca do tema.

\section{CAMINHOS INVESTIGATIVOS}

A pesquisa de campo foi realizada por meio de entrevista semiestruturada, elaborada sob os preceitos da história oral temática (MEIHY, 1994). As entrevistas foram realizadas em novembro e dezembro de 2017 com cinco mulheres integrantes da equipe Atenah, que competiram em nível nacional e internacional.

Como as atletas na atualidade residem em lugares diferentes, duas em São Paulo, uma na França, uma na Nova Zelândia e outra na Espanha, optou-se por realizar as entrevistas por meio de chamada de vídeo no WhatsApp, o que permitiu que a pesquisadora e a informante se vissem e ouvissem em tempo real; porém, somente o áudio das entrevistas foi gravado. Embora haja algumas desvantagens em entrevistar por esse meio, como eventuais problemas técnicos, são vantagens de entrevistas on-line a capacidade de alcançar informantes distantes, permitirem espaço seguro e conveniente para os participantes (como sua própria casa) e a abertura para repetir respostas e perguntas (SEITZ, 2016).

As entrevistas foram realizadas após parecer favorável do Comitê de Ética e Pesquisa com Seres Humanos da Universidade Federal de Juiz de Fora, aprovado em 7 de novembro de 2017, sob o número 2.369.017. As participantes foram esclarecidas da natureza da pesquisa e concordaram com o Termo de Consentimento Livre e Esclarecido. Dada a representatividade das entrevistadas no esporte, somada à intenção de melhor contextualização da análise, solicitou-se a autorização do uso de seus nomes nas publicações resultantes deste estudo. As entrevistas foram transcritas de acordo com o Manual Básico do Centro de Memória do Esporte (GOELLNER, 2012) e analisadas a partir dos preceitos da Análise de Conteúdo (AC) (BARDIN, 2008). O Quadro 1 representa as atletas com suas respectivas identificações. 
Quadro 1 - Identificação das atletas da equipe Atenah

\begin{tabular}{|c|c|c|c|c|c|}
\hline & $\begin{array}{c}\text { Sílvia } \\
\text { Guimarães }\end{array}$ & $\begin{array}{c}\text { Eleonora } \\
\text { Audrá }\end{array}$ & $\begin{array}{l}\text { Karina } \\
\text { Lefrève }\end{array}$ & $\begin{array}{c}\text { Marcela } \\
\text { Toldi }\end{array}$ & $\begin{array}{c}\text { Fernanda } \\
\text { Maciel }\end{array}$ \\
\hline IDADE & 41 & 39 & 39 & 33 & 38 \\
\hline NACIONALIDADE & Brasileira & Brasileira & Brasileira & Brasileira & Brasileira \\
\hline NATURALIDADE & São Paulo & São Paulo & São Paulo & São Paulo & $\begin{array}{c}\text { Belo } \\
\text { Horizonte }\end{array}$ \\
\hline RESIDÊNCIA & São Paulo & $\begin{array}{l}\text { Christchurch, } \\
\text { Nova Zelândia }\end{array}$ & $\begin{array}{c}\text { Miramar, } \\
\text { França }\end{array}$ & São Paulo & $\begin{array}{l}\text { Anserall, } \\
\text { Espanha }\end{array}$ \\
\hline \begin{tabular}{|l|} 
ETNIA \\
AUTODECLARADA
\end{tabular} & Parda & Branca & Branca & Branca & Branca \\
\hline ESTADO CIVIL & Casada & Casada & Casada & Casada & Divorciada \\
\hline FILHOS & Um & Um & Dois. & Não & Não \\
\hline $\begin{array}{l}\text { ESCOLARIDADE/ } \\
\text { FORMAÇÃO }\end{array}$ & $\begin{array}{c}\text { Graduação } \\
\text { em } \\
\text { Pedagogia }\end{array}$ & $\begin{array}{c}\text { Graduação em } \\
\text { Desenho } \\
\text { Industrial }\end{array}$ & $\begin{array}{c}\text { Superior } \\
\text { incompleto } \\
\text { em Educação } \\
\text { Física } \\
\end{array}$ & $\begin{array}{l}\text { Graduação em } \\
\text { Administração }\end{array}$ & $\begin{array}{l}\text { Bacharel } \\
\text { em Direito } \\
\text { e Nutrição } \\
\text { Esportiva } \\
\end{array}$ \\
\hline PROFISSÃO & Pedagoga & $\begin{array}{l}\text { Organizadora } \\
\text { de eventos }\end{array}$ & $\begin{array}{l}\text { Agricultora e } \\
\text { Técnica de } \\
\text { Basquete }\end{array}$ & $\begin{array}{c}\text { Administradora, } \\
\text { empresária } \\
\text { e atleta } \\
\text { profissional }\end{array}$ & $\begin{array}{c}\text { Atleta } \\
\text { profissional } \\
\text { e empresária }\end{array}$ \\
\hline
\end{tabular}

Fonte: Elaborado pelas autoras

\section{RESULTADOS E DISCUSSÕES}

\subsection{A EQUIPE ATENAH: SURGIMENTO E FORMAÇÃO}

Segundo Silvia Guimarães (em entrevista), Atenah foi uma equipe de corrida de aventura composta por integrantes mulheres, idealizada no ano 2000 pelas atletas Sílvia Guimarães (Shubi) e Eleonora Audrá (Nora) e concebida com o objetivo de participar das principais provas de CA do Brasil e do mundo. Essa equipe se manteve no cenário competitivo da CA entre os anos de 2000 a 2009. Durante grande parte do período de existência da equipe, as atletas dedicaram-se integralmente ao esporte. As atletas naturais de São Paulo treinavam juntas em sua terra natal e nos arredores, sempre que podiam. Fernanda treinava em Minas Gerais. A equipe também treinava nas próprias competições (já que participava de muitas).

Na primeira participação da equipe, em abril de 2000, em um percurso de 800 (oitocentos) quilômetros, dentre as trinta equipes participantes, a Atenah conquistou um honroso oitavo lugar, em que apenas nove equipes conseguiram realizar o percurso completo. Segundo Sílvia Guimarães (em entrevista), tal resultado gerou um grande retorno da mídia, o que foi positivo, inclusive para o crescimento da equipe. No mesmo ano, a equipe Atenah sagrou-se campeã do Circuito Brasileiro de CA, na Expedição Mata Atlântica, na cidade de Bertioga (SP), em que as jovens surpreenderam todas as outras equipes tradicionais - geralmente três homens e uma mulher, realizando um longo trecho de trekking trotando e correndo em vez de caminhar, como era costume entre os(as) atletas, apresentando um excelente preparo físico. Essa emocionante vitória foi relatada para a revista Go Outside por 
Cristina Carvalho, atleta da equipe, que faleceu em 2015 por consequência de um câncer de mama (GO OUTSIDE, 2011).

Ainda no ano 2000, a equipe participou da épica Eco-Challenge Adventure Race, na Malásia, conquistando a vigésima posição. Segundo Wladimir Togumi (2017), esse pode ser considerado o evento de CA mais famoso do mundo, pois, em 1996, a competição foi transmitida pelo Discovery Channel.

No ano de 2001, a Eco-Challenge foi sediada na Nova Zelândia, e a equipe Atenah ficou em vigésimo oitavo lugar, entre outras equipes de formação tradicional. Em 2002, a equipe conquistou o oitavo lugar na tradicional competição Raid Gauloises, que ocorreu no Vietnã. A Raid Gauloises é considerada por muitos a primeira corrida de aventura moderna, pois seu organizador, o jornalista francês Gérard Fusil, com o objetivo de criar o maior evento de resistência do planeta, realizou, em 1989, uma corrida com experiências que lembraram a era de exploração global. Com a ajuda de sua esposa, Nelly, Fusil criou conceitos que hoje são características fundamentais na CA, como os postos de controle (PC), as áreas de transição (AT), a característica expedicionária e autossustentável, a obrigatoriedade de equipes com integrantes de ambos os gêneros e a orientação (TOGUMI, 2017).

No período entre 2000 e 2009, as atletas participaram das principais competições expedicionárias de CA no Brasil e no mundo, como a Southern Traverse; edições da Eco-Challenge, na Nova Zelândia e Ilhas Fiji; Campeonato Mundial na Escócia; Ecomotion Pro; Brasil Wild e outras. Entre outros destaques, estão o quarto lugar na "Terra Incógnita", em 2004, na Croácia, e um inesquecível quarto lugar na Ecomotion Pro de 2006, sendo a primeira equipe brasileira a cruzar o pórtico (TOGUMI, 2017).

O desejo de formar uma equipe exclusiva de mulheres surgiu pelo descontentamento das atletas com o desempenho dos homens. Ironicamente, esse aspecto constitui um paradoxo com o histórico da participação das mulheres na maioria dos esportes de aventura na natureza, nos quais, comumente, elas são vistas como mais fracas e menos competentes que os homens.

Foi no final do EMA 99 [...] Todas nós tínhamos competido em equipes diferentes e todas nós tivemos problemas com os homens [risos] das nossas equipes. [...] Ninguém conhecia muito o esporte, era difícil de regular, de começar, balancear o ritmo. E os homens sempre acabavam indo muito mais [...] rápido, mais forte do que precisavam e... E acabava que no final da prova eles estavam bem mais destruídos que nós, mulheres (Eleonora Audrá).

As atletas da Atenah se inseriram na CA por volta dos 20 anos de idade, todas por convite de homens, como amigos, primos ou conhecidos. Esse fato remete ao pensamento de que a obrigatoriedade de equipes mistas de gênero pode contribuir para a inserção das mulheres nesse esporte. Contudo, se não houvesse tal exigência, talvez as equipes fossem formadas exclusivamente por homens.

[...] um amigo meu me liga um dia e fala: 'Ah, Shubi, vai ter uma corrida aqui no Brasil que tem que remar, pedalar e andar no mato, vai ser na llha Bela, você quer fazer?'. E eu, ah, quero. E aí era o primeiro EMA né, foi o EMA 1998, foi a primeira corrida que teve aqui no Brasil (Sílvia Guimarães). 
Em 1998 [...] Alexandre Freitas fez a primeira... O primeiro EMA no Brasil, né, e aí eu fui [...] meu primo que me iniciou nas pedaladas que me chamou, porque precisava de uma equipe mista [...] (Karina Lefrève).

Nas narrativas das atletas da equipe Atenah, é possível identificar a obrigatoriedade da presença da mulher na equipe como ponto positivo para sua inserção no esporte.

[...] a regra [...] naquela época, era uma mulher por equipe. Aí a gente começou a ir muito bem nas provas, que a gente passou a ganhar prova [...] aí mudaram a regra né, aí a regra virou um do sexo oposto... Aí a gente começou a fazer algumas corridas com um homem, porque era obrigatório (Sílvia Guimarães).

[...] Tem uma equipe aqui precisando de uma mulher, você quer fazer? Ah, sim, claro [...] Mas eu acho que o maior desafio no começo era encontrar qual era o melhor equilíbrio de uma equipe, dos integrantes dentro de uma equipe (Eleonora Audrá).

Além disso, é importante destacar que, na fala de Sílvia Guimarães, fica claro que a variação da regra entre as provas, no que se refere à formação das equipes, permitia à Atenah competir com equipe exclusiva de mulheres, ou convidar um integrante homem, caso a regra assim exigisse. Esse fato leva a pensar que, em algum momento na história da CA, a equipe Atenah incomodou, o que levou os organizadores a elaborarem melhor a redação de seus regulamentos, de forma a não haver brecha na interpretação que pudesse permitir uma equipe exclusiva de mulheres.

Ao criar a equipe Atenah, essas atletas ousaram, transgrediram a tradição da formação das equipes na CA, desafiando os limites entre as masculinidades e as feminilidades normativas, bem como borraram a delimitação da natureza como espaço de domínio masculino. As provas prediletas da Atenah eram as "corridas de expedição" (geralmente de cinco a dez dias). Essas provas exigem que os(as) participantes formem equipes com meses de antecedência. Em preparação para a corrida, as equipes, além de levantarem fundos para financiar custos das provas, precisam equipar e treinar todos os membros.

Os membros devem ter habilidades específicas em atividades de alto risco, como técnicas de escalada, orientação, canyoning, mountain biking e outras. Eles devem treinar até vinte horas por semana enquanto equilibram - às vezes, sacrificam - o trabalho e a vida familiar. Uma vez em curso, os(as) atletas são obrigados(as) a suportar privação de sono, dor, perdade peso, doença, lesão, condições meteorológicas extremas e terreno hostil. Os(as) atletas devem administrar e transportar durante dias seus alimentos, água e equipamentos e continuamente passar por áreas isoladas e desconhecidas, com o mínimo de descanso e/ou sono (KAY; LABERGE, 2004). Com base nessas características, tornou-se instigante investigar a participação feminina nessa atividade esportiva, aos olhos das próprias atletas.

\subsection{MULHERES: TRANSGREDINDO, RESISTINDO E DESAFIANDO OS LIMITES NA CA}

Nos esportes ligados à natureza, segundo Barbara Humberstone (2007), as hierarquias de gênero tradicionais são comumente reforçadas; contudo, em alguns 
casos, podem oferecer oportunidades de transgressão e resistência. Estudos apontam que as mulheres, ao longo da história, superam barreiras culturalmente impostas para se inserirem no campo dos esportes de aventura em diferentes modalidades (FIGUEIRA, 2008; KAY; LABERGE, 2004; KNIJNIK; HORTON; CRUZ, 2010; LARENDEAU; SHARARA, 2008; LIPPA, 2010; ROBERTSON, 2003; SCHWARTZ et al., 2013; SISJORD, 2013; THORPE, 2011). Entretanto, elas são praticamente invisíveis, e suas conquistas representam pouco, perto dos desafios que ainda enfrentam. Por conseguinte, os esportes de aventura são dominados pela participação de homens e, geralmente, percebidos como masculinos, pelas características das vestimentas, estilo dos praticantes, expressões e jargões (ANDERSON, 1999; FORD; BROWN, 2006; THORPE, 2011).

O campo da Corrida de Aventura não foge à regra, e o domínio dos homens é facilmente percebido. Em estudo anterior, no qual foram analisadas as representações de gênero na mídia sobre a $C A$, verificou-se que as reportagens representam as mulheres atletas de CA como deusas e musas e, embora exaltem sua coragem, reforçam sua sub-representação no esporte, ao Ihes atribuírem, na equipe, papéis como cuidadora, mediadora de conflitos e responsável pela alimentação. Na maioria das vezes, essas mulheres são veiculadas nos discursos midiáticos muito mais por sua beleza física e coragem do que por sua competência, conhecimento e resistência para a prática do esporte (SILVA; MOURÃO, 2017).

Gisele Schwartz e colaboradores (2013) investigaram a aceitação, por parte dos homens, bem como possíveis atitudes e condutas preconceituosas, no que tange à presença feminina nos esportes de aventura, no olhar de atletas já consagrados no Brasil. Os(as) autores(as) concluíram que, conquanto a presença feminina nos esportes de aventura venha se disseminando, muitos entraves ainda se fazem presentes, tais como: fatores financeiros; restrita oportunidade de participação em eventos competitivos; dificuldades no deslocamento para locais de treino; dificuldade de conciliação da carreira esportiva com a vida pessoal, profissional e familiar. As mulheres que participaram desse estudo também relataram situações de preconceito - mesmo que de forma velada - por parte dos homens. Entre outras formas de preconceito, estão aquelas que consideram que esses esportes são estritamente masculinos e desvalorizam a capacidade e a habilidade, assim como a força e a resistência da mulher. Importante ressaltar que os fatores relatados podem significar motivos de impedimento para que outras mulheres venham a praticar essas atividades.

Os resultados do presente estudo corroboram os achados de Joanne Kay e Suzanne Laberge (2004), em estudo denominado "Mandatory Equipment: Women in Adventure Race". Nesse estudo, as pesquisadoras utilizam as concepções de "campo" e "poder simbólico" de Pierre Bourdieu (2012) como arcabouço teórico, para explicar a CA como processo social dotado de um sistema simbólico construído simultaneamente por discurso e prática. Conquanto a regra da competição garanta a permanência das mulheres no esporte, enredada por um discurso igualitário, na prática, a naturalização da diferença-fraqueza das mulheres e o privilégio da força física (atribuída aos homens) como "capital dominante no campo" legitimam a dominação dos homens na CA. 
O "campo", segundo Bourdieu (2012), pode ser entendido como uma arena social, um espaço de conflito e competição, no qual as lutas acontecem pelo acúmulo de diferentes formas de "capital simbólico" (físico, social, cultural, econômico etc.) nele valorizadas. O capital simbólico, portanto, confere prestígio, distinção, influência e poder a quem o detém. Dentro de um campo, as lutas dos agentes sociais ocorrem não apenas sobre formas particulares de capital nele eficazes, mas, também, sobre a própria definição de qual forma de capital é mais valorizada (o capital simbólico dominante).

O "poder simbólico", segundo Bourdieu (2012), é um poder invisível, quase mágico, que permite conquistar o equivalente àquilo que é obtido pela força (física ou econômica). Esse poder arbitrário só pode ser exercido com a cumplicidade daqueles que não reconhecem estarem sujeitos a ele, ou o exercerem. Agentes sociais que possuem o "capital simbólico" dominante em um campo detêm o "poder simbólico" dele.

A "regra de gênero", que exige que as equipes sejam mistas, não apenas como prova da resistência das mulheres, mas como demonstração de que a "especialização" específica das equipes é importante, está presente no discurso dos praticantes de $\mathrm{CA}$, os quais, embora reconheçam as habilidades físicas das mulheres, sugerem que sua especificidade (em equipe) é valorizada em relação à força física associada ao sexo masculino. Ou seja, a gestão de risco, considerada chave no sucesso nas provas de $\mathrm{CA}$, é uma qualidade atribuída com mais frequência às mulheres. Assim, o discurso da CA dá prioridade à gestão de risco (atribuída às mulheres) como mais fundamental numa equipe, do que a resistência/força física (atribuída aos homens), parecendo, ao menos em nível do discurso, constituir um local de desporto igualitário - se não feminino - tendencioso (KAY; LABERGE, 2004).

Matthew Atencio e colaboradores (2009), em estudo realizado também à luz dos pensamentos de Bourdieu, analisaram a mídia especializada de skateboarding e concluíram que tal segmento mantém as divisões de gênero baseadas na lógica do individualismo e da incorporação do "habitus masculino", associado ao risco e à proeza, resultando em recompensa com capital social e cultural. Já a concepção de "habitus feminino" está associada à falta de habilidade e aversão ao risco, resultando em participantes inautênticas nesse campo social.

Dani Abulhawa (2008) também estudou as relações de gênero no campo do skateboarding. Essa autora concluiu que, por mais que essa organização social tenha um discurso anti-hegemônico, paradoxalmente, apresenta um sexismo inerente, com foco no heteromasculino, no qual as mulheres ocupam uma posição que a autora chamou de edgeland, ou seja, permanecem marginalmente envolvidas nessa subcultura.

As atletas da Atenah, quando questionadas sobre a falta da presença de um homem na equipe, mencionaram a força física como atributo masculino e, portanto, uma fraqueza em seu time, reforçando essa qualidade como "capital dominante no campo". Porém, ao mesmo tempo, demonstraram ironia na narrativa, como que reforçando um estereótipo de gênero. 
Não, pra não dizer que não tem vontade de ter homem na equipe, foram alguns poucos momentos [...] É sempre quando tem que carregar o caiaque pra algum lugar [risos] na hora da força física, da pura força física [riso] [...] (Sílvia Guimarães).

Quando tem que carregar muito peso assim [risos]. Sinto falta de um homem [risos]. Mas depende também, né, porque às vezes que você acha que vai ajudar e atrapalha [risos] (Eleonora Audrá).

Segundo Bourdieu (2017, p. 54):

[...] as próprias mulheres aplicam a toda realidade e, particularmente, às relações de poder em que se veem envolvidas, esquemas de pensamento, que são produto da incorporação dessas relações de poder e que se expressam nas oposições fundadoras da ordem simbólica [...].

Ou seja, as mulheres aplicam categorias construídas do ponto de vista dos homens (dominantes) às relações de dominação, o que as faz (categorias) serem vistas como naturais.

A relação de dominação entre os gêneros está fundamentada na estrutura de um "mercado de bens simbólicos", no qual o homem é o agente e as mulheres são tratadas como objetos que nele circulam (BOURDIEU, 2017). Neste sentido, pode-se pensar na CA como um mercado de bens simbólicos, no qual as mulheres são valorizadas como moedas de troca entre as equipes. Ainda nesta perspectiva, talvez seja possível compreender a alta circulação das mulheres entre as equipes tradicionais de corrida de aventura. Entretanto, com a criação da equipe Atenah, essas mulheres subverteram a ordem natural desse esporte, comumente dominado por homens. Deixaram de ser representadas como moeda de troca, para se tornarem agentes no processo de formação e gerência de sua própria equipe. Esta equipe deu visibilidade à competência das mulheres para a CA e desnaturalizou o esporte como um espaço de domínio masculino, inclusive na performance, com seus grandes resultados.

\subsection{DAS DIFICULDADES ÀS ESTRATÉGIAS DE PARTICIPAÇÃO UTILIZADAS PELAS ATLETAS DE CA}

Nos estudos de Kay e Laberge (2004), as mulheres de equipes tradicionais utilizavam-se de "estratégias de conservação" para acumular diferentes formas de capital simbólico, reificando sua própria subordinação. Porém, as atletas da Atenah, ao formarem uma equipe exclusiva de mulheres, utilizaram-se de "estratégias de subversão", travando, no campo, mesmo que não intencionalmente, uma luta por poder na CA.

Segundo Bourdieu (2012), mesmo que essas estratégias sejam orientadas por interesses, elas não são o resultado da escolha racional, mas geradas pelo que o sociólogo chamou de "sentido prático" ou "sentir pelo jogo", ou seja, a forma prática como os agentes sociais respondem às oportunidades e restrições de uma determinada circunstância, de acordo com sua posição de poder, em um campo. Portanto, a formação da equipe Atenah foi possível porque as atletas gozavam de capital simbólico (físico, financeiro, cognitivo e social). 
Em uma das competições da equipe Atenah, observa-se um paradoxo nas estratégias utilizadas. Em ocasião da "Terra Incógnita", em 2004, na Croácia:

[...] Tiveram várias etapas de remo na Croácia e [...] remo é uma modalidade que pra mulher é muito difícil [...] Na verdade a gente chegou em terceiro lugar, mas eles arrumaram um jeito de dar uma zona lá nos resultados e colocar a gente em quarto, pra não pagar premiação, mas a gente foi super bem [...] (Marcela Toldi).

Mas você acredita... Nessa questão do resultado. Você acredita que foi pelo fato de serem mulheres? Uma equipe exclusiva de mulheres? (Fabiana Silva - Pesquisadora).

Não. Ele convidou, na verdade a equipe, então ele deu a inscrição pra gente [...] Eu acho que ele queria premiar em dinheiro aqueles que tinham pagado pra fazer a prova, sabe? A gente foi lá mais por marketing, que ele não convidou nenhuma outra equipe [...] Mas foi superlegal. Foi fantástica a experiência (Marcela Toldi).

Observa-se que, ao mesmo tempo em que se utilizaram de uma "estratégia de subversão", por participarem da prova com uma equipe exclusiva de mulheres, elas também se utilizaram de "estratégias de conservação", com o objetivo de se manterem no esporte. Isto legitima, assim, sua subordinação, quando fizeram vista grossa para seus resultados e desempenho na prova.

Segundo Joanne Kay e Suzanne Laberge (2004), a CA constitui um sistema simbólico de classificação social, servindo como instrumento de dominação, legitimando a hierarquização social, estimulando, como explica Bourdieu, os dominados a aceitar as hierarquias existentes no campo. Dessa forma, o discurso das atletas evidencia que elas "jogam o jogo" da CA, ao não perceber - ou fingir não perceber - as regras da manutenção da hierarquia de gênero, pormenorizando as dificuldades enfrentadas frente às experiências positivas vividas no esporte.

Sobre as maiores dificuldades na CA, a maioria das atletas não as atribuiu ao fato de serem mulheres, mas citaram os obstáculos que qualquer atleta encontra no esporte, como sono, frio, desgaste físico, acidentes, lesões ou doenças durante a prova, e dificuldades financeiras. Apenas duas atletas mencionaram dificuldades em relação aos integrantes homens, porém uma delas ponderou, dizendo que essas dificuldades eram supridas com estratégia de equipe e outras qualidades físicas relacionadas às mulheres, como a resistência.

Eu acho que sempre nas corridas a maior dificuldade é sono [risos] [...]. Ou frio, quando faz frio. Porque brasileiro não se dá bem com frio. Mas... e também tem a parte financeira, que é sempre um desafio, né? [silêncio] (Sílvia Guimarães).

Acho que o maior perrengue que a gente passou foi quando a Nora teve uma infecção sanguínea no... Em Fiji. Ela teve que ser evacuada de helicóptero e a gente ficou meio preocupada... [trecho inaudível]. E uma vez também na Nova Zelândia, a gente tava no pico de uma montanha e eu tive uma crise de pânico (Karina Lefrève).

Corrida de aventura é um esporte caro, né, então assim, eu curti muito enquanto a gente tinha apoio e patrocínio. Então a gente pôde viver esse sonho porque, pra gente, financeiramente, foi viável assim [...] (Marcela Toldi). 
Nossa maior dificuldade, quando a gente competia com mulher, era a hora que tinha que ter mesmo [...] o físico, de carregar bastante peso (Eleonora Audrá).

Ah, era o sono mesmo [...]. Uai, assim, ser mais fraca e menos veloz que os homens. Mas em relação à resistência a gente conseguia mais ou menos estar equilibradas com eles (Fernanda Maciel).

As questões sobre estereótipos de gênero não foram centrais nas narrativas das mulheres da equipe Atenah, por se tratar de uma equipe com alta performance na CA. Essas mulheres, para competir entre mulheres, devem ter superado o gênero como uma das limitações de sua atuação no esporte.

Sobre o fim da equipe, as atletas apontaram algumas questões individuais de suas vidas: falta de recursos financeiros para continuar competindo, desejo de viver em outro país, vontade de seguir outra carreira laboral (além da esportiva), avanço da idade, entre outras. Porém, os motivos mais fortes foram o casamento e o nascimento dos filhos.

Porque a gente ficou velha [risos] [...] Não, estou brincando, foi porque... [silêncio]. Foi vida mesmo, porque assim, primeiro a Karina foi pra França, aí depois a Nora casou com o lan e está morando na Nova Zelândia [...] a Fernandinha resolveu focar na corrida de montanha, mudou pra Espanha também, então já desmantelou a equipe, né. Ficou eu e a Cris aqui e logo em seguida a Cris também ficou doente. A Cris ela teve um câncer e ela morreu em 2015. Então dispersou mesmo. Cada uma foi pra um canto, daí todo mundo foi ter filho. Eu tive filho, a Nora teve filho [...] Mas a gente em breve vai fazer uma reedição da Atenah, agora que os filhos estão crescendo [...] Eu demorei até... Eu acho que eu casei tarde por causa disso, corrida de aventura [risos]. Certeza [risos]. Passei muito tempo rodando o mundo aí em vez de procurar marido [risos] (Sílvia Guimarães).

[...] A gente cresceu [riso] e... Eu vim morar na Nova Zelândia... E a Ka... A Fernandinha mudou pra Espanha... E aí acabou ficando difícil competir... Mas as provas em si também mudaram um pouco, né... $E$ também por causa de viabilização de capital, de patrocínio [...] (Eleonora Audrá).

Porque a vida... A gente... Envelheceu, começou a ter filho [...] (Karina Lefrève).

Eu parei de competir com a Atenah porque eu comecei a trabalhar. Fiquei um pouco mais velha e daí então eu precisava ganhar um dinheiro também. [...] (Marcela Toldi).

Ah, acho que a gente cansou, né [risos] [...] A partir de um momento que você vai ficando maior, você tem... Você não tem muito tempo, né? [...] (Fernanda Maciel).

Discursos culturais sobre a maternidade, relacionados ao esporte, podem interferir nas identidades de mães atletas, ao produzirem diferentes efeitos resultantes; por exemplo: sofrimento, melhoria/redução psicológica e de desempenho e desengajamento esportivo (MCGANNON; MCMAHON; GONSALVES, 2018). Estudos evidenciam que as normas culturais de uma "boa mãe" e os cuidados "ideais" com os filhos podem dificultar o engajamento em atividade física por parte das mulheres. Essas perspectivas normativas enfatizam que as mulheres devem cuidar das crianças e colocar as necessidades da família acima das suas próprias (MILLER; BROWN, 2005). 
Esses achados sugerem que o casamento e a maternidade são uma barreira de gênero para as mulheres seguirem na carreira na CA e em diferentes esferas esportivas. Embora a Atenah tenha se dispersado, as atletas continuaram fisicamente ativas. Muitas delas ainda competem em outros esportes, duas em nível profissional, nas modalidades de ciclismo e corrida de montanha. As atletas relataram que praticam esportes outdoor com frequência. Esses comportamentos esportivos corroboram a teoria de Belinda Wheaton (2004), segundo a qual os lifestyle sports acompanham o indivíduo pela vida toda.

\section{CONSIDERAÇÕES FINAIS}

As atletas da Atenah transgrediram a norma, ao criarem uma equipe só de mulheres. Mesmo competindo contra equipes formadas majoritariamente por homens, venceram e conquistaram pódios em várias provas nacionais e internacionais. Assim, mesmo que nem sempre vencesse a competição, a Atenah vencia a disputa por espaço, em um lugar de masculinidade hegemônica, comumente associada aos esportes de aventura.

Além da motivação em criar uma equipe exclusiva de mulheres, a equipe Atenah foi idealizada, principalmente, pela insatisfação das atletas com a performance dos homens de suas equipes nas competições, gerando uma contradição diante da tradicional hierarquia de gênero na participação de mulheres nos esportes de natureza, onde elas comumente são vistas como mais frágeis e menos habilidosas. Esse fato desconstrói o determinismo biológico no campo dos esportes de aventura.

Entretanto, este estudo sugere que a inserção das mulheres no campo da corrida de aventura pode estar associada ao fato de a regra exigir equipes mistas em gênero, as quais são, até mesmo, comparadas a um "equipamento obrigatório". Ainda, apesar de a participação das mulheres nesse esporte conferir status de subversão, elas ainda são sub-representadas nos discursos, os quais Ihes atribuem habilidades específicas, como mediadoras de conflitos, cuidadoras e equilíbrio emocional da equipe. A questão do estereótipo de gênero poderia ser reformulada no roteiro de entrevista, dando ênfase ao fato de ser uma equipe de mulheres. Talvez esta tenha sido uma das limitações desta pesquisa, já que a maioria das atletas não relacionou a questão às relações de gênero.

A narrativa das atletas evidenciou, ainda, que elas reforçam a questão de habilidades específicas por gênero, sugerindo que valorizavam a força física dos homens como "capital social dominante". Foi possível constatar que as atletas, intencionalmente ou não, utilizaram estratégias para se manterem na CA, tanto para permanecerem na mesma posição do campo, as quais Pierre Bourdieu denominou de "estratégias de conservação", quanto para tomada de poder no campo: "estratégias de subversão". Portanto, entende-se que as atletas da Atenah, ao formarem uma equipe de mulheres, subverteram a norma e deixaram de ser valorizadas como "moeda de troca" no "mercado de bens simbólicos" da CA. Também é importante reforçar que o surgimento da equipe só foi possível porque as atletas gozavam de alto capital simbólico: físico, econômico, cognitivo e social. 
Mesmo com o fim da carreira esportiva das atletas da Atenah na CA, elas continuam praticando atividades físicas outdoor. Algumas ainda competem em outras modalidades, o que sugere que a aventura (na natureza) é mais que um esporte, podendo ser considerada um estilo de vida que acompanha as atletas desde a infância. O incentivo da família, tanto nas práticas esportivas na infância como na prática da CA, também foi fator fundamental para o sucesso das atletas.

As atletas da Atenah foram pioneiras, transgressoras e excepcionais no seu esporte. Entretanto, a análise dos motivos que levaram ao fim da equipe sugere que o engajamento das mulheres na corrida de aventura pode ser ameaçado pelas instituições do casamento e da maternidade. Contudo, há necessidade de novos estudos para investigar a maternidade e o envolvimento de mulheres na CA. Também sugiro outras pesquisas com mulheres e homens de equipes tradicionais para esclarecer mais sobre as relações de gênero nesse esporte.

A CA continua sendo caracterizada como uma atividade elitista, com predomínio de praticantes homens, brancos, de classe média/alta e elevado grau de instrução. Como alternativa de mudança desse panorama, sugere-se a abordagem desse esporte nas aulas de Educação Física Escolar, por meio de práticas em contato com a natureza, como trekking e aulas de orientação.

\section{REFERÊNCIAS}

ABULHAWA, Danielle. Female skateboarding: re-writing gender. Platform: Postgraduate e Journal of Theatre and Performing Arts, v. 3, n. 1, p. 56-72, 2008.

ADVENTUREMAG. Atenah nas competições internacionais. 2001. Disponível em: https:// www.adventuremag.com.br/outros/atenah/mundial.htm. Acesso em: 11 maio 2020.

ANDERSON, Kristin. The construction of gender in an emerging sport. Journal of Sport and Social Issues, v. 23, n.1, p. 55-79, 1999.

ATENCIO, Matthew; BEAL, Becky; WILSON, Charlene. The distinction of risk: urban skateboarding, street habitus and the construction of hierarchical gender relations.

Qualitative Research in Sport and Exercise, v. 1, n. 1, p. 3-20, 2009.

ATIVO. Equipe feminina Atenah volta às provas de aventura. 2009. Disponível em: https://www.ativo.com/mais-esportes/equipe-feminina-atenah-volta-as-provas-de-aventural. Acesso em: 11 maio 2020.

BARDIN, Laurence. Análise de conteúdo. São Paulo: Edições 70, 2008.

BEAL, Becky. Alternative masculinity and the effect on gender relations in the subculture of skateboarding. Journal of Sport Behaviour, v. 19, n. 3, p. 204-220, 1996.

BITENCOURT, Valeria; AMORIM, Simone. Corrida de Aventura. In. DACOSTA, Lamartine (org.). Atlas do esporte no Brasil. Rio de Janeiro: CONFEF, 2006 Disponível em: http:// www.atlasesportebrasil.org.br/textos/116.pdf. Acesso em: 15 jan. 2018.

BOURDIEU, Pierre. A dominação masculina. Tradução: Maria Helena Kühner (português de Portugal). Rio de Janeiro: Best Bolso, 2017. 
BOURDIEU, Pierre. (1930-2002). O poder simbólico. Tradução: Fernando Tomaz (português de Portugal). Rio de Janeiro: Bertrand Brasil, 2012.

FIGUEIRA, Márcia Luiza M. Skate para meninas: Modos de se fazer ver em um esporte em construção. 2008. 247 f. Dissertação (Mestrado em Educação Física) - Escola de Educação Física, Fisioterapia e Dança, Universidade Federal do Rio Grande do Sul, Porto Alegre, 2008.

FORD, Nick; BROWN, David. Surfing and social theory: Experience, embodiment and narrative of the dream glide. London; New York: Routledge, 2006.

GOELLNER, Silvana Vilodre. A contribuição dos estudos de gênero e feministas para o campo acadêmico-profissional da educação física. In: DORNELLES, Priscila Gomes; WERNETZ, lleana; SCHWENGBER, Maria Simone Vione (orgs.). Educação física e gênero: desafios educacionais. ljuí: Editora Unijuí, 2013. p. 23-43.

GOELLNER, Silvana Vilodre. Projeto garimpando memórias: manual básico do Centro de Memória do Esporte. Porto Alegre, CEME, 2012.

GOOUTSIDE. Memórias de uma Atenah. 2011. Disponível em: https://gooutside.com. br/699-memorias-de-uma-atenah/. Acesso em: 11 maio 2020.

HUMBERSTONE, Barbara. 'Transgressões de gênero e naturezas contestadas'. Revista Brasileira de Ciências do Esporte, v. 28, n. 3, p. 21-38, 2007.

KAY, Joanne; LABERGE, Suzanne. Mandatory equipment. Women in adventure racing. In: WHEATON, Belinda. Understanding lifestyle sports. Consumption, identity and difference. London: Routledge, 2004. p.154-174.

KNIJNIK, Jorge Dorfman; HORTON, Peter; CRUZ, Livia Oliveira. Rhizomatic bodies, gendered waves: transitional femininities in Brazilian surf. Sport in Society, v.13, n. 7/8, p. 1170-1185, 2010.

LARENDEAU, Jason; SHARARA, Nancy. Women could be every bit as good as guys. Reproductive and resistance agency in two 'action' sports. Journal of Sport and Social Issues, v. 32, n. 1, p. 24-47, 2008.

LIPPA, Richard. A. Sex differences in personality traits and gender-related occupational preferences across 53 nations: testing evolutionary and social-environmental theories. Archives of Sexual Behavior, v. 39, n. 3, p. 619-636, 2010.

MCGANNON, Kerry; MCMAHON, Jenny; GONSALVES, Christine. Juggling motherhood and sport: A qualitative study of the negotiation of competitive recreational athlete mother identities. Psychology of Sport \& Exercise, v. 36, p. 41-49, 2018.

MEIHY, José Carlos Sebe Bom. Definindo história oral e memória. Cadernos CERU. Serie 2, n. 5, p. 52-60, 1994.

MILLER, Yvette; BROWN, Wend. Determinants of active leisure for women with young children - an "ethic of care" prevails. Leisure Sciences, v. 27, p. 405-420, 2005.

PFEIFFER, Ronald; KRONISH, Robert. Off-road cycling injuries: an overview. Sports Med [online], Auckland, v. 19, n. 5, p. 225 -311, 1995. Disponível em: https://link.springer.com/ article/10.2165/00007256-199519050-00002. Acesso em: 15 maio 2018.

ROBERTSON, Janet. The magnificent mountain women: adventures in the Colorado Rockies. 2. ed. Lincoln: University of Nebraska, 2003. 
SCHWARTZ, Gisele Maria; FIGUEIREDO, Juliana de Paula; PEREIRA, Leonardo Madeira; CHRISTOFOLETTI, Danielle Ferreira Auriemo; DIAS, Viviane Kawano. Preconceito e esportes de aventura: a (não) presença feminina. Motricidade, v. 9, n. 1, p. 57-68, 2013.

SEITZ, Sally. Pixilated partnerships, overcoming obstacles in qualitative interviews via skype: A research note. Qualitative Research, v.16, n.2, p. 229-235, 2016. Disponível em: https:// journals.sagepub.com/doi/full/10.1177/1468794115577011. Acesso em: 10 jun. 2018.

SILVA, Fabiana Duarte; MOURÃO, Ludmila Nunes. Representações de gênero na mídia sobre a corrida de aventura. In: SEMINÁRIO INTERNACIONAL FAZENDO GÊNERO/ WOMEN'S WORLDS CONGRESS, 11-13, 2017, Florianópolis. Anais Eletrônicos.

Disponível em: http://www.en.wwc2017.eventos.dype.com.br/resources/anais/1499439252 ARQUIVO_07.07.2017-ArtigoMM_FG.pdf. Acesso em: 10 jun. 2019.

SISJORD, Mari Kristin. Women battling for a space in snowboarding. In: PFISTER, Gertrud; SISJORD, Mari Kristin. Gender and sport: Changes and challenges. Münster: Waxmann, 2013. p. 123-139.

THORPE, Holly. Snowboarding bodies in theory and practice. New York: Palgrave Macmillan, 2011.

TOGUMI, Wladimir. A corrida de aventura. In: FONSECA, Caco. Corrida de aventura: a natureza é nosso desafio. São Paulo. Editora Labrador, 2017, p. 13-25.

WEATON, Belinda. Understanding Lifestyle Sports: Consumption, identity and difference. Oxfordshire. Routledge, 2004. 
Abstract: This research investigated the histories of athletes in the all-female adventure race (AR) team Atenah. AR is a multi-sport competition of mixed teams with at least one person whose gender is different from the other members'. This qualitative, descriptive study consisted of a semi-structured interview with Atenah's five members. The athletes use 'subversion' and 'conservation' strategies, according to Bourdieu, and establish 'agency,' according to Dworkin and Messner. That they organized an all-female team can be understood as a 'subversion strategy' or the establishment of 'resistant agency.' Paradoxically, Athena's athletes also used 'conservation strategies' to remain in sports, thus creating 'reproductive agency.' Therefore, their families' support and encouragement were crucial to their success, but women's engagement in adventure race may be threatened by marriage and motherhood as institutions.

Keywords: Sports. Nature. Gender studies. Women.

Resumen: Este artículo investigó la trayectoria deportiva de las atletas del equipo de carrera de aventura (CA) Atenah, formado exclusivamente por mujeres. La CA es una competencia multideportiva, formada por equipos mixtos, con al menos una persona de género diferente de los otros miembros. La investigación cualitativa de carácter descriptivo consistió en entrevista semiestructurada con cinco atletas del equipo Atenah. Se observó que las atletas utilizan estrategias de "subversión" y "conservación", según Bourdieu, y constituyen "agencias", según la teoría de Dworkin y Messner. El hecho de que organicen un equipo exclusivamente femenino puede entenderse como "estrategia de subversión" o la constitución de "agencia resistente". Paradójicamente, utilizaron "estrategias de conservación" para mantenerse en el deporte, configurando así "agencia reproductiva". Se concluye que el apoyo e incentivo de la familia fue fundamental para el éxito de las atletas; sin embargo, el compromiso de las mujeres en la carrera de aventura puede verse amenazado por las instituciones del matrimonio y la maternidad.

Palabras clave: Deportes. Naturaleza. Estudios de Género. Mujeres. 


\section{LICENÇA DE USO}

Este é um artigo publicado em acesso aberto (Open Access) sob a licença Creative Commons Atribuição 4.0 Internacional (CC BY 4.0), que permite uso, distribuição e reprodução em qualquer meio, desde que o trabalho original seja corretamente citado. Mais informações em: http://creativecommons.org/licenses/by/4.0

\section{CONFLITO DE INTERESSES}

Os autores declararam que não há conflito de interesses neste trabalho.

\section{DECLARAÇÃO DE APROVAÇÃO EM COMITÊ DE PESQUISA}

As entrevistas foram realizadas após parecer favorável do Comitê de Ética e Pesquisa com Seres Humanos da Universidade Federal de Juiz de Fora, aprovado em 07 de novembro de 2017, sob o número 2.369.017. As participantes foram esclarecidas da natureza da pesquisa e concordaram com o Termo de Consentimento Livre e Esclarecido

\section{CONTRIBUIÇÕES AUTORAIS}

Fabiana Duarte e Silva: coleta e análise de dados da pesquisa e redação do manuscrito.

Ludmila Mourão: orientadora da pesquisa e participou da revisão do manuscrito.

Gisele Maria Schwartz: coorientadora da pesquisa e contribuiu com sugestões e revisão do manuscrito.

Bruna Silveira Chaves: revisão e formatação do manuscrito, além de sugestões de melhoria na redação do mesmo.

\section{FINANCIAMENTO}

O presente trabalho foi realizado com apoio da Coordenação de Aperfeiçoamento de Pessoal de Nível Superior - Brasil (CAPES) - Código de Financiamento 001 na concessão de dois meses de bolsa de estudos e da Prefeitura de Juiz de Fora, por meio de licença remunerada para aperfeiçoamento profissional da primeira autora.

\section{COMO REFERENCIAR}

SILVA, Fabiana Duarte e; MOURÃO, Ludmila; SCHWARTZ, Gisele Maria; CHAVES, Bruna Silveira. Memórias de Atenah: trajetórias de mulheres brasileiras na corrida de aventura. Movimento, v. 26, p. e26076, jan./ dez. 2020. Disponível em: https://seer.ufrgs.br/Movimento/article/view/100848 Acessado em: 28 nov.

2020. DOI: https://doi.org/10.22456/1982-8918.1008488

\section{RESPONSABILIDADES EDITORIAIS}

Alex Branco Fraga*, Elisandro Schultz Wittizorecki*, Ileana Wenetz ${ }^{* *}$, Ivone Job*, Mauro Myskiw*, Raquel da Silveira*

*Universidade Federal do Rio Grande do Sul, Escola de Educação Física, Fisioterapia e Dança, Porto Alegre, RS, Brasil

**Universidade Federal do Espirito Santo (UFES). Centro de Educação Física e Desportos (CEFD), Vitória/ES, Brasil 